\title{
Successful maintenance of a stingless bee population despite a severe genetic bottleneck
}

\author{
Denise Araujo Alves - Vera Lucia Imperatriz-Fonseca • \\ Tiago Maurício Francoy • Pérsio Souza Santos-Filho • \\ Johan Billen · Tom Wenseleers
}

Received: 23 July 2010/ Accepted: 30 November 2010

(C) Springer Science+Business Media B.V. 2010

\begin{abstract}
Stingless bees play an important ecological role as pollinators of many wild plant species in the tropics and have significant potential for the pollination of agricultural crops. Nevertheless, conservation efforts as well as commercial breeding programmes require better guidelines on the amount of genetic variation that is needed to maintain viable populations. In this context, we carried out a long-term genetic study on the stingless bee Melipona scutellaris to evaluate the population viability consequences of prolonged breeding from a small number of founder colonies. In particular, it was artificially imposed a genetic bottleneck by setting up a population starting from only two founder colonies, and continued breeding from it for a period of over 10 years in a location outside its natural area of occurrence. We show that despite a great reduction in the number of alleles present at both neutral microsatellite loci and the sex-determining locus relative to its natural source population, and an increased frequency in the production of sterile diploid males, the genetically impoverished population could be successfully bred and maintained for at least 10 years. This shows that in stingless bees, breeding from a small stock of colonies may have less severe consequences than previously suspected.
\end{abstract}

D. A. Alves ( $₫)$ · V. L. Imperatriz-Fonseca · P. S. Santos-Filho Bee Laboratory, Bioscience Institute, University of São Paulo, Rua do Matão Trav. 14, 321, 05508-090 São Paulo, Brazil e-mail: daalves@ib.usp.br

\section{T. M. Francoy}

School of Arts, Sciences and Humanities, University of São Paulo, Rua Arlindo Béttio 1000, 03828-000 São Paulo, Brazil

J. Billen · T. Wenseleers

Laboratory of Entomology, Zoological Institute, Catholic

University of Leuven, Naamsestraat 59, 3000 Leuven, Belgium
In addition, we provide a simulation model to determine the number of colonies that are needed to maintain a certain number of sex alleles in a population, thereby providing useful guidelines for stingless bee breeding and conservation efforts.

Keywords Diploid male production - Conservation genetics - Small population - Stingless bees - Meliponini

\section{Introduction}

Pollination by animals is considered a key ecosystem service (Costanza et al. 1997), and bees play a crucial role in this as important vectors for the efficient and effective sexual reproduction of many wild plants and commercial crops (Kearns et al. 1998; Slaa et al. 2006). However, anthropogenic changes, such as deforestation, agricultural intensification and pollution, have contributed to the decline or even the extinction of many native and managed bee populations, with severe negative consequences for both natural ecosystems and agriculture (Biesmeijer et al. 2006; Goulson et al. 2008).

Bees have special needs with regard to suitable nesting sites and floral resources and habitat loss is one of the major threats to their continued survival (Goulson et al. 2008). In addition, population reduction and habitat fragmentation lead to genetic bottlenecks and increased genetic drift and hence to a much reduced genetic diversity, which can negatively affect population viability (Goulson et al. 2008; Zayed 2009). Indeed, due to the complementary sex determination system (CSD; Whiting 1943), bees and other haplodiploid insects are expected to be unusually vulnerable to such genetic impoverishment, since the loss of alleles at the sex locus will lead to an increased production 
of sterile diploid males (Cook and Crozier 1995; Packer and Owen 2001). Under a CSD sex determination system, diploid individuals that are heterozygous at the sex locus develop into females, whereas haploid hemizygous and diploid homozygous individuals develop into males (Whiting 1943). The loss of genetic diversity in bee populations therefore leads to an increased chance for queens to make matched matings, i.e. to mate with haploid males sharing identical sex alleles (Whiting 1943; Cook and Crozier 1995; Zayed 2009), and this will result in an increased production of diploid males (Zayed et al. 2004). The production of diploid males is highly disadvantageous and imposes a large cost (Cook and Crozier 1995; Zayed et al. 2004; Zayed and Packer 2005; Heimpel and de Boer 2008), since diploid males are usually either unviable or sterile (Cook and Crozier 1995; Heimpel and de Boer 2008), or only able to father sterile triploid offspring (Cook and Crozier 1995). Indeed, simulation models have shown that diploid male production alone can elevate the base extinction risk in haplodiploids by over an order of magnitude relative to that caused by inbreeding depression in threatened diploids (Zayed and Packer 2005). In addition, for eusocial species, the production of diploid males will slow down colony growth and increase colony mortality (Ross and Fletcher 1986; Cook and Crozier 1995), since a large proportion of the female worker-destined progeny will end up developing into diploid males, which do not contribute any colony resources (Chapman and Bourke 2001).

Stingless bees are the most diverse group of all eusocial bees and can be found in most tropical or subtropical regions of the world (Michener 1974). They are characterised by having perennial colonies composed of a few hundreds to ca. 10,000 workers and typically, a single, once-mated queen (Peters et al. 1999). Stingless bees of the genus Melipona comprise approximately 65 species distributed throughout the Neotropical region (Camargo and Pedro 2007). They nest in tree cavities in which the bees store pollen and honey in large egg-shaped pots (Michener 1974), which are frequently harvested by local beekeepers (Cortopassi-Laurino et al. 2006). In addition, Melipona species are major pollinators of a wide variety of wild plants and agricultural crops that have flowers with poricidal anthers that release pollen through the bees' vibrations (Heard 1999), and are therefore of great importance for the conservation of natural biodiversity in the tropics. Unlike bumblebees (Slaa et al. 2006), however, stingless bees have as yet not been commercially bred on a large scale for pollination purposes, although they have been shown to have great potential for the pollination of many crops, including avocado, coconut, coffee, guava, mango and rose apple grown in open culture, as well as for strawberry, sweet pepper and tomato kept under greenhouse conditions (Heard 1999; Slaa et al. 2006). One factor that has hampered the large-scale deployment of stingless bees for pollination purposes is that little information is available on how successful breeding programmes should be set up (Cortopassi-Laurino et al. 2006), for example with respect to the amount of genetic variation and the number of sex alleles that are needed to maintain viable populations. Indeed, there is a long-standing controversy between Brazilian scientists Warwick Kerr and Paulo Nogueira-Neto over the number of colonies required to maintain viable stingless bee populations, with the former arguing that about 6 sex alleles and ca. 40 colonies would be required (Kerr and Vencovsky 1982), but with the latter believing from experience that only a few colonies (ca. 2, Nogueira-Neto 2002) could be enough. In addition, currently only few estimates are available of the number of sex alleles present in managed Melipona populations (Kerr 1987; Aidar and Kerr 2001; Carvalho 2001), and none of these studies have considered the genetic consequences of prolongued breeding of stingless bee colonies from a limited stock.

In this context, we carried out a long-term genetic study on the stingless bee Melipona scutellaris in order to evaluate the population viability consequences of prolonged breeding from a small number of founder colonies. In particular, it was artificially imposed a genetic bottleneck by setting up a population starting from only two founder colonies, and continued breeding from it for a period of over 10 years in a location outside its natural area of occurrence. Subsequently, we compared the frequency of the production of diploid males and the number of sex alleles that are present in the small and isolated managed population and the large, managed source population that is located in the species' natural area of occurrence. In addition, we provide simulation models and analytical equations to determine the number of colonies that are needed to maintain a certain number of sex alleles in a population, thereby providing useful guidelines for stingless bee breeding and conservation programmes.

\section{Materials and methods}

\section{Study organism}

The geographic distribution of $M$. scutellaris covers the Atlantic Rainforest areas in the Northeast of Brazil (Camargo and Pedro 2007), where it uses hollow trees as protected cavities for nesting. Their perennial nests are composed of egg-shaped pots in which they store honey and pollen and multilayered horizontal brood combs with same-sized cells, from which workers, queens and males 
are reared. All cells are constructed, mass-provisioned with liquid larval food and are sealed by the workers immediately after egg deposition (Michener 1974). A colony consists of one functional single-mated queen, ca. 2,000 workers (Peters et al. 1999; Tóth et al. 2004), and some males and virgin queens. In the Northeast of Brazil, M. scutellaris is intensively reared, due to the amount and quality of its honey (Cortopassi-Laurino et al. 2006; Carvalho-Zilse et al. 2009). In addition, $M$. scutellaris is a key pollinator for a large number of commercial crops, such as avocado, guava and rose apple (Castro 2002).

\section{Study sites}

We carried out this study with managed colonies kept in stingless bees apiaries (known as meliponaries) inside and outside their natural area of occurrence (at Granja São Saruê, Igarassu, Pernambuco state, $7^{\circ} 50^{\prime} 3.74^{\prime \prime}$ S $34^{\circ} 54^{\prime} 22.87^{\prime \prime} \mathrm{W}$, and the Aretuzina Farm, São Simão, São Paulo state, $21^{\circ} 26^{\prime} 25.97^{\prime \prime} \mathrm{S} 47^{\circ} 34^{\prime} 54.65^{\prime \prime} \mathrm{W}$, located over $1,100 \mathrm{~km}$ south of the most Southern range of this species, Alves et al. in press). In Igarassu, the beekeeper increased the number of colonies from 200 to 750 in 5 years by splitting nests (Cortopassi-Laurino et al. 2006) and in addition to this high number of managed colonies that were kept, the meliponary was also surrounded by a forested area, where wild nests can be found housing in tree cavities. In S. Simão, where M. scutellaris is kept outside its natural range, the population was started from only two founder colonies which were obtained from Igarassu in 1996 (Nogueira-Neto 2002) and which after a breeding programme of 10 years increased to about 55. No gene flow could have occured after the experiment was started, given that the most Southern natural range of M. scutellaris stretches only up to Lafaiete Coutinho in Bahia State (Alves et al. in press).

\section{Sampling}

Between January 2006 and May 2007, we collected stingless bees from 38 and 18 colonies maintained in wooden free-foraging nest boxes in Igarassu and S. Simão (Table 1). We collected 10 worker pupae and any male pupae that we could find directly from the comb, after which we preserved them in absolute ethanol for genetic analysis; the remainder of the brood was reintroduced back into the natal nest. For the S. Simão population, some colonies were resampled when the mother queen (which was individually marked) was replaced by a new one, which resulted in the collection of brood derived from 24 distinct queens (Table 1).
Genetic analysis of diploid male production

To check for diploid male production we genotyped all the collected male brood from all the brood combs that contained more than $5 \%$ of males ( $n=38$ colonies; Table 1$)$. Those containing fewer males could be inferred not to produce diploid males, given that the production of $5 \%$ males was significantly lower than the expected $50 \%$ if a queen had made a matched mating (one-sided binomial test, $P<10^{-15}$ given that the collected combs contained 65-524 cells with diploid brood (avg. 231)). We genotyped 10 worker pupae and an average of 11 male pupae (range 7-23, total 404; Table 1) from 38 colonies in Igarassu and 18 in S. Simão at three microsatellite loci, Mbi-201, Mbi254 (Peters et al. 1998), and T4-171 (Paxton et al. 1999), which were the most variable in this species in a preliminary screening of a total of 10 loci. DNA was extracted using the Chelex method and microsatellites were amplified using multiplex PCR reactions, followed by a touchdown programme, as described in Alves et al. (2009). After amplification, $1 \mu \mathrm{l}$ of the PCR product was mixed with $8.8 \mu \mathrm{l}$ formamide and $0.2 \mu \mathrm{l}$ Genescan 500 LIZ size standard (Applied Biosystems, Lennik, Belgium) and loaded onto an ABI-3130 Avant capillary sequencer. Alleles were called using the supplied Gene Mapper software and checked by eye.

We reconstructed the genotype of each mother queen and that of her mate from the genotypes of the diploid brood she produced. This was straightforward, given that in all cases, genotypes were consistent with the mother queens being singly mated and with just a single matriline being present. We categorized males as haploid if they were homozygous at all loci and as diploid if they were heterozygous at one or more loci and carried both paternal and maternal alleles. In order to guarantee the accuracy of all male genotypes, we re-amplified, rescored and rechecked all male genotypes that appeared to suggest that they were diploid. The percentage of diploid brood that consisted of diploid males was estimated as

$p=\frac{M(D /(D+H))}{M(D /(D+H))+F}$

where $M$ and $F$ were the number of males and females (gynes and workers) collected from each comb and $D$ and $H$ were the number of diploid and haploid males among the genotyped males. For queens that had made a matched mating, we checked for deviations from the expected percentage of 50\% using the parametric bootstrap method (Efron and Tibshirani 1993) followed by a Bonferroni correction for multiple testing, assuming that $M$ and $D$ were binomially distributed and using $1,000,000$ bootstrap replicates. Deviations from the expected 50:50 ratio could arise either as a result of occasional double mating 
Table 1 Melipona scutellaris colonies kept in Igarassu (IG) and São Simão (SS) with information on the total number of pupae and percentage of males present in the sampled brood combs, the number of workers and males genotyped and the estimated percentage of diploid brood that was male

\begin{tabular}{|c|c|c|c|c|c|c|c|}
\hline \multirow{2}{*}{$\begin{array}{l}\text { Colony and } \\
\text { queen }^{\mathrm{a}}\end{array}$} & \multirow{2}{*}{$\begin{array}{l}\text { Collection } \\
\text { date }\end{array}$} & \multicolumn{2}{|c|}{ Sampled brood combs } & \multicolumn{3}{|c|}{ Number of individuals genotyped ${ }^{b}$} & \multirow{2}{*}{$\begin{array}{l}\text { Estimated \% of } \\
\text { diploid brood male }\end{array}$} \\
\hline & & $\begin{array}{l}\text { Number } \\
\text { of pupae }\end{array}$ & $\begin{array}{l}\text { Percentage } \\
\text { of males }\end{array}$ & Workers & $\begin{array}{l}\text { Haploid } \\
\text { males }\end{array}$ & $\begin{array}{l}\text { Diploid } \\
\text { males }\end{array}$ & \\
\hline IG 01-a & Sep. 2006 & 441 & 36.05 & 10 & 14 & 0 & 0.00 \\
\hline IG $02-\mathrm{a}$ & Jan. 2006 & 288 & 0.00 & & & & 0.00 \\
\hline IG $03-\mathrm{a}$ & Jan. 2006 & 386 & 16.06 & 10 & 8 & 0 & 0.00 \\
\hline IG 04-a & Jan. 2006 & 199 & 0.00 & & & & 0.00 \\
\hline IG $05-\mathrm{a}$ & Sep. 2006 & 341 & 18.48 & 10 & 9 & 0 & 0.00 \\
\hline IG 06-a & Sep. 2006 & 426 & 24.41 & 10 & 10 & 0 & 0.00 \\
\hline IG $07-a$ & Jan. 2006 & 281 & 0.00 & & & & 0.00 \\
\hline IG $08-\mathrm{a}$ & Jan. 2006 & 323 & 8.36 & 10 & 9 & 0 & 0.00 \\
\hline IG 09-a & Jan. 2006 & 100 & 0.00 & & & & 0.00 \\
\hline IG $10-\mathrm{a}$ & May 2007 & 102 & 0.00 & & & & 0.00 \\
\hline IG $11-\mathrm{a}$ & Sep. 2006 & 488 & 45.08 & 10 & 9 & 0 & 0.00 \\
\hline IG $12-\mathrm{a}$ & Jan. 2006 & 380 & 28.42 & 10 & 9 & 0 & 0.00 \\
\hline IG $13-\mathrm{a}$ & Jan. 2006 & 365 & 28.77 & 10 & 9 & 0 & 0.00 \\
\hline IG 14-a & Jan. 2006 & 164 & 2.44 & & & & 0.00 \\
\hline IG $15-\mathrm{a}$ & Jan. 2006 & 525 & 0.19 & & & & 0.00 \\
\hline IG $16-\mathrm{a}$ & Jan. 2006 & 282 & 33.69 & 10 & 8 & 0 & 0.00 \\
\hline IG $17-\mathrm{a}$ & Jan. 2006 & 188 & 0.00 & & & & 0.00 \\
\hline IG $18-\mathrm{a}$ & Jan. 2006 & 241 & 19.09 & 10 & 10 & 0 & 0.00 \\
\hline IG $19-\mathrm{a}$ & May 2007 & 455 & 21.10 & 10 & 8 & 0 & 0.00 \\
\hline IG $20-\mathrm{a}$ & May 2007 & 368 & 17.93 & 10 & 10 & 0 & 0.00 \\
\hline IG $21-\mathrm{a}$ & May 2007 & 66 & 1.52 & & & & 0.00 \\
\hline IG $22-\mathrm{a}$ & Sep. 2006 & 87 & 0.00 & & & & 0.00 \\
\hline IG $23-\mathrm{a}$ & Sep. 2006 & 269 & 1.86 & & & & 0.00 \\
\hline IG 24-a & Sep. 2006 & 162 & 0.00 & & & & 0.00 \\
\hline IG $25-\mathrm{a}$ & Sep. 2006 & 123 & 0.00 & & & & 0.00 \\
\hline IG 26-a & Sep. 2006 & 282 & 21.99 & 10 & 10 & 0 & 0.00 \\
\hline IG $27-\mathrm{a}$ & Sep. 2006 & 314 & 6.37 & 10 & 10 & 0 & 0.00 \\
\hline IG $28-\mathrm{a}$ & Sep. 2006 & 191 & 0.00 & & & & 0.00 \\
\hline IG $29-\mathrm{a}$ & Sep. 2006 & 328 & 0.00 & & & & 0.00 \\
\hline IG $30-\mathrm{a}$ & Sep. 2006 & 326 & 19.63 & 10 & 10 & 0 & 0.00 \\
\hline IG $31-\mathrm{a}$ & Sep. 2006 & 265 & 0.00 & & & & 0.00 \\
\hline IG 32-a & May 2007 & 72 & 0.00 & & & & 0.00 \\
\hline IG 33-a & May 2007 & 366 & 0.00 & & & & 0.00 \\
\hline IG 34-a & May 2007 & 162 & 0.00 & & & & 0.00 \\
\hline IG $35-\mathrm{a}$ & May 2007 & 262 & 47.33 & 10 & 1 & 9 & 44.71 \\
\hline IG 36-a & May 2007 & 217 & 29.03 & 10 & 10 & 0 & 0.00 \\
\hline IG 38-a & May 2007 & 176 & 0.57 & & & & 0.00 \\
\hline IG 39-a & May 2007 & 423 & 9.69 & 10 & 12 & 0 & 0.00 \\
\hline \multicolumn{4}{|c|}{ Proportion of colonies that produced diploid males } & & $2.63 \%$ & & \\
\hline SS 01-a & Mar. 2006 & 279 & 66.31 & 10 & 7 & 3 & 37.12 \\
\hline SS 02-a & Mar. 2006 & 445 & 51.46 & 10 & 0 & 10 & 51.46 \\
\hline SS 02-b & Feb. 2007 & 201 & 8.96 & 10 & 10 & 0 & 0.00 \\
\hline SS 04-a & Apr. 2006 & 247 & 13.77 & 10 & 10 & 0 & 0.00 \\
\hline SS 06-a & Jul. 2006 & 347 & 15.85 & 10 & 8 & 0 & 0.00 \\
\hline SS 06-b & Dec. 2006 & 195 & 5.13 & 10 & 9 & 0 & 0.00 \\
\hline SS 08-a & Mar. 2006 & 244 & 61.89 & 10 & 5 & 4 & 41.92 \\
\hline
\end{tabular}


Table 1 continued

\begin{tabular}{|c|c|c|c|c|c|c|c|}
\hline \multirow{2}{*}{$\begin{array}{l}\text { Colony and } \\
\text { queen }^{\mathrm{a}}\end{array}$} & \multirow{2}{*}{$\begin{array}{l}\text { Collection } \\
\text { date }\end{array}$} & \multicolumn{2}{|c|}{ Sampled brood combs } & \multicolumn{3}{|c|}{ Number of individuals genotyped ${ }^{\mathrm{b}}$} & \multirow{2}{*}{$\begin{array}{l}\text { Estimated \% of } \\
\text { diploid brood male }\end{array}$} \\
\hline & & $\begin{array}{l}\text { Number } \\
\text { of pupae }\end{array}$ & $\begin{array}{l}\text { Percentage } \\
\text { of males }\end{array}$ & Workers & $\begin{array}{l}\text { Haploid } \\
\text { males }\end{array}$ & $\begin{array}{l}\text { Diploid } \\
\text { males }\end{array}$ & \\
\hline SS 08-b & Oct. 2006 & 329 & 17.02 & 10 & 10 & 0 & 0.00 \\
\hline SS 10-a & Jan. 2007 & 295 & 52.54 & 10 & 0 & 10 & 52.54 \\
\hline SS $15-\mathrm{a}$ & Mar. 2006 & 457 & 21.01 & 10 & 11 & 0 & 0.00 \\
\hline SS $25-\mathrm{a}$ & Sep. 2006 & 201 & 0.50 & & & & 0.00 \\
\hline SS 28-a & Aug. 2006 & 511 & 42.47 & 10 & 16 & 0 & 0.00 \\
\hline SS 34-a & Mar. 2006 & 403 & 0.00 & & & & 0.00 \\
\hline SS 36-a & Mar. 2006 & 354 & 5.65 & 10 & 7 & 0 & 0.00 \\
\hline SS 36-b & Nov. 2006 & 320 & 69.69 & 10 & 8 & 5 & 46.93 \\
\hline SS 43-a & Jul. 2006 & 479 & 19.42 & 10 & 10 & 0 & 0.00 \\
\hline SS $55-\mathrm{a}$ & Sep. 2006 & 425 & 0.00 & & & & 0.00 \\
\hline SS 59-a & Sep. 2006 & 724 & 24.72 & 10 & 23 & 0 & 0.00 \\
\hline SS 59-b & Jan. 2007 & 381 & 38.06 & 10 & 20 & 0 & 0.00 \\
\hline SS 63-a & Apr. 2006 & 408 & 55.39 & 10 & 7 & 7 & 38.31 \\
\hline SS 63-b & Nov. 2006 & 440 & 10.00 & 10 & 9 & 0 & 0.00 \\
\hline SS 66-a & Sep. 2006 & 281 & 14.95 & 10 & 10 & 0 & 0.00 \\
\hline SS 67-a & Jan. 2007 & 386 & 13.73 & 10 & 10 & 0 & 0.00 \\
\hline SS 72-a & Jan. 2007 & 275 & 1.45 & & & & \\
\hline \multicolumn{5}{|c|}{ Proportion of colonies that produced diploid males } & \multicolumn{3}{|l|}{$25.00 \%$} \\
\hline
\end{tabular}

a The letters in the colony codes refer to the succession of different mother queens

${ }^{\mathrm{b}}$ Brood samples were not genotyped if they did not contain male brood or males were present in percentages lower than $5 \%$ in the sampled combs

c Based on Eq. 1

(Carvalho 2001) or due to some of the diploid males being unviable.

The probability $P^{\prime}$ of diploid males erroneously being misclassified as haploid ones due to such individuals being homozygous at all three loci investigated can be calculated as the product of the homozygosity at all loci, and was 0.069 for S. Simão and 0.022 for Igarassu. Nevertheless, given that approximately 10 males were genotyped per colony and that ca. two thirds of these, i.e. about 7 , would be expected to be diploid in colonies producing diploid males, the average probability of misclassifying a colony producing diploid males as one producing haploid males only was negligibly small, $P^{\prime}=7$, i.e. $7 \times 10^{-9}$ for $\mathrm{S}$. Simao and $2 \times 10^{-12}$ for Igarassu.

Relative life expectancy of queens that had made a matched mating

In order to determine the longevity of queens that had or had not made a matched mating we transferred 10 M. scutellaris colonies headed by newly mated queens from Igarassu to free-foraging nestboxes in the bee laboratory at the University of São Paulo (São Paulo, São Paulo state, 2333'37.41"S 4643'53.04"W). Subsequently, we monitored the colonies for queen replacement events, by marking all mother queens with a coloured plastic tag on their thorax, and regularly checked all queens over a total period of ca. 3 years. Subsequently, female and male pupae were sampled before and after each queen replacement event, and genotyped as described above. Since $M$. scutellaris does not naturally occur in São Paulo state and given the small population size, we expected matched matings to occur by chance.

Estimation of the number of sex alleles

The effective number of sex alleles present in each population was estimated using the equation of Laidlaw et al. (1956):

$k_{e}=\frac{2(N+1)}{H+1}$

where $k_{e}$ is the effective number of sex alleles, $N$ is the total number of colonies sampled and $H$ is the expected number of colonies that produced diploid males out of a given total number of colonies. Given that the life expectancy of 
queens producing diploid males was only half as long as those producing haploid males (see Results), the power $p$ to detect colonies producing diploid males using our sampling scheme was only $50 \%$. Hence, $H$ was estimated as the observed number of colonies producing diploid males $H_{o b s}$ ' p. $95 \%$ confidence limits on $n$ were calculated using the parametric bootstrap method using the percentile method and 1,000,000 bootstrap replicates (Efron and Tibshirani 1998), assuming that $H$ was binomially distributed and taking $p$ as a constant.

Effect of a population bottleneck on the sampled number of sex alleles

The effect of starting a population from a small number of initial colonies is expected to greatly reduce the number of sex alleles present in the population. To quantify this effect we used a simple stochastic simulation model in Wolfram Mathematica in which we determined the expected number of sampled sex alleles as a function of the number of colonies used to set up a new isolated population and the number of sex alleles present in the source population, assuming that these would be present in the population in approximately equal frequencies. The source population was taken to comprise 1,000 colonies. $95 \%$ confidence limits on the expected number of sampled sex alleles were calculated as the 2.5 and $97.5 \%$ percentiles of the distribution of estimates obtained by repeating the simulation 1,000 times (Efron and Tibshirani 1986).

Decline in the number of sex alleles over multiple generations

Over multiple generations, the number of sex alleles in a small population is expected to further decline as a result of drift. Nevertheless, because of selection against common alleles (which will tend to be eliminated as a result of matched matings), this decline is expected to proceed more slowly than for neutral alleles (Kimura and Crow 1964; Yokoyama and Nei 1979). To determine the speed at which sex alleles would be lost by drift from the S. Simão population, we again used a stochastic Mathematica simulation model, which was set up as follows: (a) we started the simulation with an initial population of 2 colonies containing a total of 5 sex alleles (the most parsimonious estimate, see Results), (b) queens died and were superseded at a constant rate of $1 / 87$ and 1/175 days for queens that had or had not made a matched mating (these mortality rates correspond to the reciprocal of the mean life expectancies of queens, see Results), (c) new queens were always assumed to be daughters of the superseded queen (occasionally queens in this species are superseded by unrelated queens that fly in from other colonies (Wenseleers et al. 2011), but this is rare enough that it could be ignored in the present context) and were allowed to mate with a random male in the population, (d) $23 \%$ of the males were assumed to be the workers' sons and $77 \%$ the queen's sons (Alves et al. 2009) and (e) the population was allowed to grow via colony splitting at an observed rate of ca. 5 colonies per year. This simulation was then run for a period corresponding to 10 years, and at each point in time the effective number of alleles (Kimura and Crow 1964) that were present in the population was calculated. The same simulation was then repeated for unlinked neutral loci, as well as for the case where the population would have been started from a larger number of 5 founder colonies containing 12 alleles. Subsequently, 95\% confidence intervals on the means were calculated as the 2.5 and $97.5 \%$ percentiles of the estimates obtained over 1,000 simulation runs.

Estimating the number of breeding colonies

from the number of sex alleles

After many generations, the number of sex alleles maintained in a population will be set by a balance between drift and mutation (Kimura and Crow 1964; Yokoyama and Nei 1979; Cornuet 1980). Yokoyama and Nei (1979) showed that the effective number of sex alleles that can be maintained in a finite population $k_{e}$ is given by

$k_{e}=\frac{1}{\sqrt{-\frac{3}{4 N_{e}} \operatorname{Ln}\left(\mu \sqrt{12 \pi N_{e}}\right)}}$

where $\mu$ is the rate of mutation to new sex alleles and $N_{e}$ is the effective size of the population. By solving Eq. 3 for $N_{e}$, the effective population size given the presence of $k_{e}$ sex alleles can therefore be estimated as

$N_{e}=\frac{3}{8} k_{e}^{2}$ ProductLog $\left(\frac{2}{9 \pi k_{e}^{2} \mu^{2}}\right)$

Following Kerr (1986), we assume in our calculations that $\mu \cong 1.6 \times 10^{-6}$, which is also in line with more recent estimates based on molecular evidence in Apis honeybees (Hasselmann et al. 2008).

The effective population size $N_{e}$ for social Hymenoptera has been calculated to be

$N_{e}=\frac{(3-p)^{2} N_{f} N_{m}}{2 N_{f}+(2-p)^{2} N_{m}}$

where $p$ is the proportion of males that are workers' sons (which in this equation are all assumed to be produced by different egg-laying workers) and $N_{f}$ and $N_{m}$ are the effective number of breeding queens and males in the population (Owen and Owen 1989). For stingless bees, where queens mate only once (Peters et al. 1999) $N_{f}=N_{m}=C$, the effective number of breeding colonies, 
whereas for honeybees, where queens are multiple mated (Estoup et al. 1994), $N_{f}=C$ and $N_{m}=M_{e} C$, where $M_{e}$ is the effective queen mating frequency. From this, the effective number of breeding colonies in the population $C$ corresponding to a certain effective population size can be calculated as

$C=\frac{N_{e}\left(2+(2-p)^{2} M_{e}\right)}{(3-p)^{2} M_{e}}$

where for stingless bees $M_{e}=1$ and $p$ can range between 0 to 1, depending on the species (Tóth et al. 2004), whereas for A. mellifera $M_{e} \cong 12.4$ (Estoup et al. 1994) and $p \cong 0$ (Visscher 1989).

\section{Results}

\section{Neutral genetic variation}

The three microsatellite loci used were reasonably polymorphic with a total of 8,5 and 7 alleles present at loci Mbi-201, Mbi-254 and T4-171. Nevertheless, as expected, the genetic variation was much reduced in the bottlenecked S. Simão population (allelic richness: 3, 3, 4; expected heterozygosity: 61, 64, and 51\%; effective number of alleles: 2.6, 2.8, 2.0) compared to the Igarassu source population (allelic richness: 8, 5, 7; expected heterozygosity: 77, 64, and 74\%; effective number of alleles: 4.3 , $2.8,3.8)$. Hence, the average allelic richness and the mean effective number of alleles present were reduced by ca. $50 \%$ and $32 \%$ in S. Simão compared to the Igarassu population. As expected from the large separation between the S. Simão population and the native range of this species (over $1,100 \mathrm{~km}$, Alves et al. in press), there was also no genetic evidence for any gene flow having occurred after the start of the experiment. For example, we did not find any unique alleles in the S. Simao population which did not occur in the native Igarassu source population.

\section{Diploid male production}

Out of 404 males genotyped, 48 (11.88\%) were heterozygous at one or more loci, and were therefore definitely diploid males (Table 1). In addition, the observed proportion of colonies producing diploid males $\left(H_{o b s}\right)$ in the $\mathrm{S}$. Simão population $(6 / 24=25.0 \%)$ was significantly higher than in the Igarassu source population $(1 / 38=2.6 \%)$ (GLZ with binomial error structure and logit link function, log-likelihood $=-18.1204$, one-sided $P=0.003$ ), as expected given that it underwent an extreme genetic bottleneck. Given that in S. Paulo two mother queens that produced diploid males survived only half as long (for 59 and 115 days, i.e. for an average of 87 days) as 18 queens who did not produce diploid males (median life expectancy 175 days, Kaplan-Meier analysis), the estimated true proportion of newly established queens that would have produced diploid males was ca. twice as high, i.e. 12/ $24=50.0 \%$ in S. Simão and $2 / 38=5.4 \%$ in Igarassu.

As expected, colonies producing diploid males had higher mean proportions of males in their brood combs $($ mean \pm S.D. $=57.80 \pm 8.30 \%$; range $47.33-69.69 \%$ ) than colonies that just produced haploid males (mean \pm S.D. $=21.17 \% \pm 10.65$; range $5.13-45.08 \%$ ) (Table 1). In addition, in none of the 7 colonies where queens had made a matched mating did the estimated percentage of diploid brood that was male deviate from the expected 50\% (Table 1, parametric bootstrap method, $P>0.05$ ). This provides additional independent evidence for single mating and also shows that diploid males did not have a lower viability than haploid ones.

Estimated number of sex alleles and effective population size

From Eq. 2 (Laidlaw et al. 1956) and the observed frequency of colonies producing diploid males, we estimate that the Igarassu source population contained an effective number of 25.9 sex alleles (95\% CL [11.1-78.0], Table 2). The S. Simão population, by contrast, was estimated to contain a much reduced effective number of sex alleles of only 3.8 (95\% CL [2.4-6.0], Table 2), as expected, given the imposed genetic bottleneck. Given an estimated effective number of 25.9 sex alleles being present in the Igarassu population, an estimated mutation rate $\mu$ of $1.6 \times 10^{-6}$ (Kerr 1986) and the fact that in Melipona scutellaris $23 \%$ of the males are workers' sons, we can also estimate that the source population must have had an effective size of ca. 3,732 (Eq. 4), which corresponds to ca. 2,497 effectively breeding colonies (Eq. 6, Owen and Owen 1989), or a colony density of ca. 8.3 colonies per hectare (given a male flight range of ca. $1 \mathrm{~km}$ and a circular mating area of ca. $3 \mathrm{~km}^{2}$, Carvalho-Zilse and Kerr 2004) (Table 2).

\section{Simulation results}

Our simulation results demonstrate that the low number of sex alleles present in S. Simão was mainly the result of the severe population bottleneck that was imposed by starting a population from only two source colonies. In fact, sampling two colonies from a source population containing an effective number of 25 sex alleles results in the sampling of an average number of 5.4 sex alleles (95\% CL [4.0-6.0]), which is close to our estimate obtained after 10 years of continued breeding (3.8 sex alleles). This means that only 


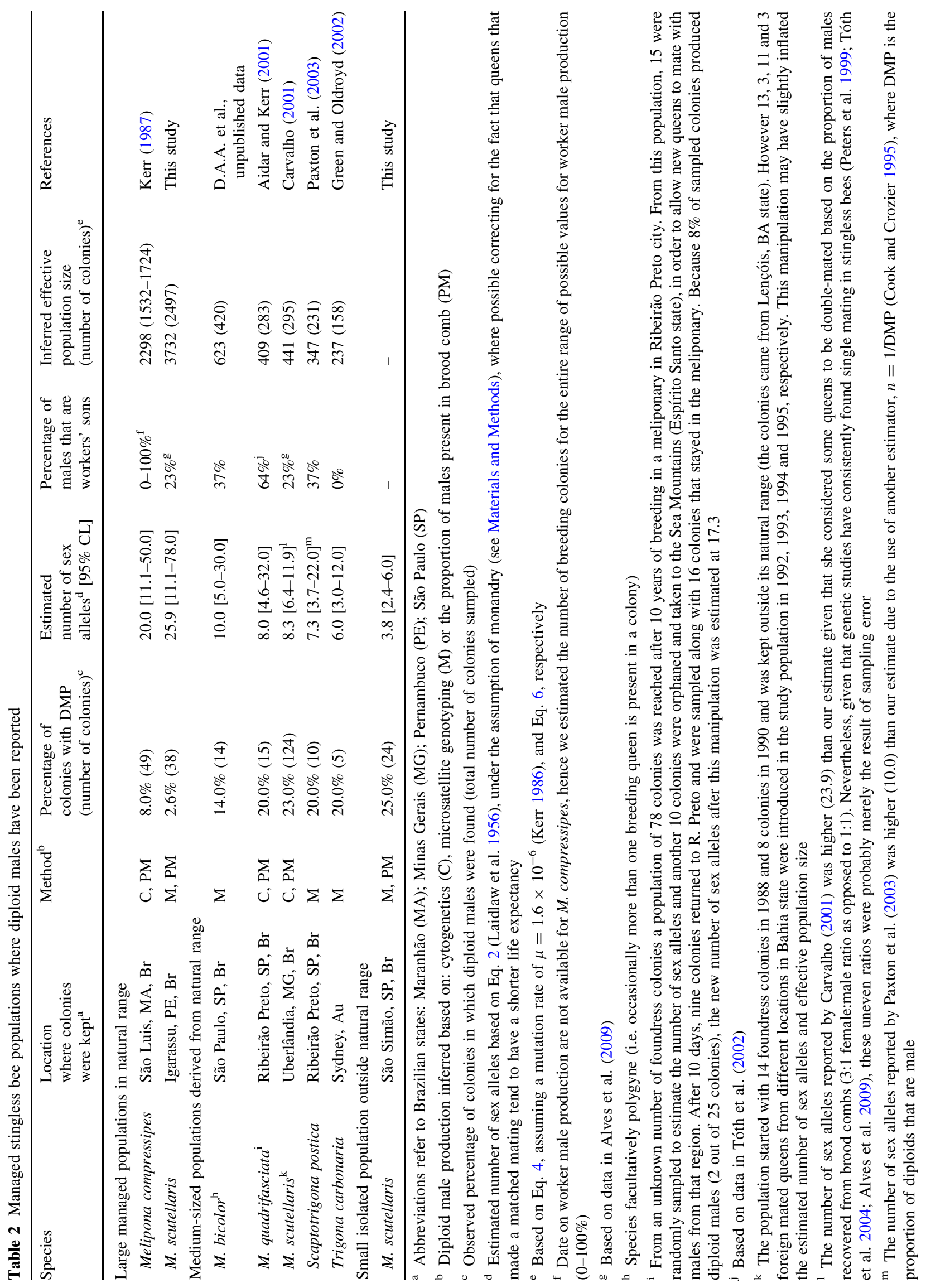




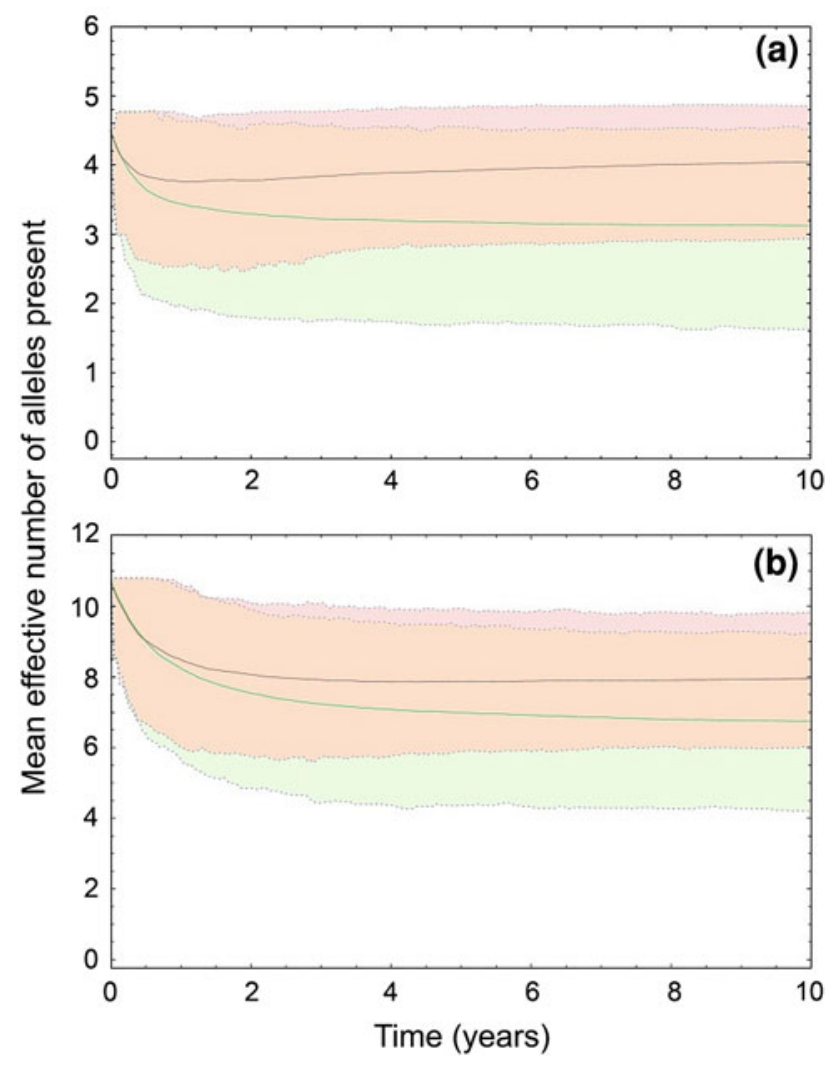

Fig. 1 Expected decline in the mean effective number of alleles present at the sex locus (upper curve) and unlinked neutral loci (lower curve) in a Melipona scutellaris bee population, starting from (a) an initial number of 2 founder colonies containing 5 alleles and (b) 5 founder colonies containing 12 alleles, assuming single mating, a constant population growth of 5 colonies per year, a constant mortality rate of $1 / 87$ and $1 / 175$ days for queens that had or had not made a matched mating and with $23 \%$ of the males being workers' sons (Alves et al. 2009). Lightly shaded areas represent the $95 \%$ confidence intervals, calculated as the 2.5 and $97.5 \%$ percentiles of the estimates obtained over 1,000 simulation runs

very few-if any-sex alleles were lost by drift in the S. Simão population, an idea that is further reinforced by our simulations which show that alleles at the sex locus are lost by drift at a very low rate, and at a much lower rate than for neutral loci (Fig. 1). This is due to the strong balancing selection at the sex locus, which favours rare alleles and tends to keep the different sex alleles in approximately equal frequencies, thereby reducing the likelihood of drift (Fig. 1; Kimura and Crow 1964; Yokoyama and Nei 1979; Page and Marks 1982; Zayed et al. 2007).

\section{Discussion}

Our results demonstrate that imposing a severe bottleneck in the stingless bee $M$. scutellaris resulted in a drastic decrease in the genetic variability and allelic richness, both at neutral loci and at the sex locus, and in a marked increase in the production of sterile diploid males. In particular, the estimated effective number of sex alleles decreased from 25.9 in the Igarassu source population to 3.8 in the bottlenecked S. Simão population, resulting in almost half of all queens making matched matings in the bottlenecked population. Surprisingly enough, however, given adequate management, the bottlenecked population could be successfully bred and maintained for over 10 years and grew at a constant rate of ca. 5 colonies per year up until the very end of our study. This shows that in stingless bees, breeding from a small stock of colonies may have less severe consequences than previously suspected (Kerr and Vencovsky 1982; Carvalho 2001; Zayed and Packer 2005; Zayed 2009). So far, only few examples are known in the social Hymenoptera of successful bottlenecked populations (e.g., in the fire ant Solenopsis invicta, Ross and Fletcher 1986, in the bumblebee Bombus terrestris, Schmid-Hempel et al. 2007, and the solitary bee Lasioglossum leucozonium, Zayed et al. 2007), which may indicate that stingless bee populations are perhaps less sensitive to genetic bottlenecks and that they can tolerate lower numbers of sex alleles in their populations.

Why would this be so? Undoubtedly, one factor that helped the S. Simão population survive and reduced the negative impact of diploid male production was the applied artificial colony management, which involved providing abundant floral resources and artificial feeding and moving brood combs from strong to weak colonies (Nogueira-Neto 2002). Another important factor, however, which may contribute to diploid males having only a moderate effect on the viability of stingless bee populations is that in stingless bees, mother queens producing diploid males tend to be killed by the workers (Camargo 1979). In stingless bees the brood is reared in sealed, mass provisioned cells (Michener 1974) which results in adult workers being unable to eliminate diploid males at an early stage, unlike in honeybees where brood in reared in open cells (Woyke 1963). Nevertheless, in M. quadrifasciata it has been shown that queens that had made a matched mating are killed by the workers within 6-30 days after diploid males first begin to emerge (Camargo 1979). Indeed, in M. scutellaris, our results show that two queens which produced diploid males were replaced by another queen within an average time of ca. 40 days (range 11-67 days) after their first brood began to emerge (accounting for the fact that the developmental time from egg to adult in M. scutellaris is nearly 48 days). The replacement of queens that had made a matched mating evidently limits the negative effects of the production of diploid males and of having small numbers of sex alleles in the population.

If we compare our results with those obtained for other native stingless bee populations (Table 2), we can see that they are also generally characterised by having relatively 
low numbers of sex alleles (6-9), small estimated effective population sizes (237-547) and a small corresponding number of effectively breeding colonies (158-368). Honeybees, by comparison, generally have much larger effective population sizes (ca. 2,000 for African honeybees, corresponding to ca. 1,000 breeding colonies, Eq. 6, Estoup et al. 1995), and therefore tend to maintain much higher numbers of sex alleles in their populations (ca. 17, Adams et al. 1977). The larger effective population size of honeybees compared to stingless bees is due to the fact that honeybees are bred on a much larger scale (De la Rúa et al. 2009) than most stingless bee species and that they are multiple mated (Estoup et al. 1994), which for a given number of breeding colonies will result in a higher effective population size compared to stingless bees where queens are single mated (Peters et al. 1999; Tóth et al. 2004). On the other hand, two stingless bees, M. compressipes and M. scutellaris, are also bred on a large scale in the Northeast of Brazil, with local beekeepers sometimes maintaining up to 1,500 colonies (Carvalho-Zilse et al. 2009). Consequently, in these two cases we also find large effective population sizes and high numbers of sex alleles (20-26, Table 2). In addition, the effective population size and the number of sex alleles is in these species also inflated by the common practise of exchanging nests, brood combs and mated queens among different meliponaries in different locations (Carvalho-Zilse et al. 2009; De la Rúa et al. 2009).

Our simulation results further show that population bottlenecks can potentially be a more potent cause of the loss of sex alleles in stingless bee populations than drift. This is because of the strong balancing selection at the sex locus, which favours rare alleles and disfavours common alleles, and which thereby keeps the different sex alleles in approximately equal frequencies, reducing drift (Fig. 1; Kimura and Crow 1964; Yokoyama and Nei 1979; Zayed et al. 2007). This result implies that stingless bee conservation efforts and breeding programmes should be particularly concerned with avoiding severe population bottlenecks. For example, our calculations show that if one wanted to be $95 \%$ certain of sampling at least 6 sex alleles from a source population containing 25 sex alleles, one would have to start breeding from a founder stock of at least 4 colonies, or 5 colonies if the source population contained a more moderate number of 8 sex alleles. On the other hand, if the aim is to maintain a certain number of sex alleles over very many generations, then drift too becomes important. Table 2 shows that in natural and small-scale managed populations, the number of sex alleles never appears to go below 6 . If we take this figure as the minimum required to maintain viable natural populations (cf. Kerr and Vencovsky 1982), then Eq. 3 (Yokoyama and Nei 1979) shows that with a mutation rate $\mu$ of $1.6 \times 10^{-6}$
(Kerr 1986) one would need an effective population size of at least 238 to maintain this number of sex alleles over many generations. Depending on the proportion of males that are workers' sons, this would correspond to an effective number of breeding colonies of between 159 and 179 (Eq. 6) (Owen and Owen 1989), or a colony density of at least 1 colony per 2 ha (given a male flight range of ca. $1 \mathrm{~km}$ and a circular mating area of ca. $3 \mathrm{~km}^{2}$, CarvalhoZilse and Kerr 2004). This figure is relevant in a conservation context, since deforestation in Brazil is leading to increased fragmentation of suitable habitat, thereby threatening many natural stingless bee population (Brown and Albrecht 2001). It should be noted that this figure of 159-170 colonies is also higher than the 40 colonies which were cited as being required to maintain 6 sex alleles by Kerr and Vencovsky (1982). This is because they had incorrectly assumed that worker reproduction is always present in stingless bees (which is not the case, Tóth et al. 2004), and more significantly, because in their calculations they had made the erroneous assumption that every egg laying worker inside a colony should be counted as an independently breeding female, and that worker reproduction would therefore increase effective population size. More recent calculations have shown instead that worker reproduction tends to slightly reduce the effective population size, given that worker reproduction causes an extra round of gametic sampling, thereby leading to more drift (Crozier 1976; Owen and Owen 1989, see Eq. 5).

In sum, our experiment in which a severely bottlenecked population of M. scutellaris was shown to successfully survive for over 10 years demonstrates that breeding from a small stock of stingless bee colonies may have less severe consequences than previously suspected (Kerr and Vencovsky 1982; Carvalho 2001; Zayed and Packer 2005; Zayed 2009). On the other hand, it is also clear that the colony management that was applied in the bottlenecked population, and in which weak colonies were occasionally provided with additional food and supplemented with brood from stronger colonies, may have contributed to the survival of the population. Hence, population bottlenecks may still have severe consequences for natural, unmanaged stingless bee population. In addition, in a management context, it is clear that the economic cost of the reduced productivity of bottlenecked populations as well as of the additional management required to keep such populations alive may not weigh up against the limited cost of occasionally bringing in new colonies to maintain sufficient variation at the sex locus. In this context, the analytic and simulation results we presented about the expected decline in the number of alleles at the sex locus should provide useful baseline figures to make informed management decisions in stingless bee breeding and conservation programmes. 
Acknowledgments We thank the São Paulo Research Foundation (05/58093-8 to D.A.A.; 04/15801-0 to V.L.I.F.), the National Council of Technological and Scientific Development (480957/2004-5 to V.L.I.F.) and the FWO-Flanders (to T.W. and J.B.) for financial support. We are especially thankful to Dr. P. Nogueira-Neto for providing valuable support and helpful expertise, allowing us to collect data from his hives in São Simão. We also thank Mr. F. Carvalho, Mrs. S. Carvalho and Dr. M. Cortopassi-Laurino for their help with sample collection in Igarassu. Work was carried out under permit numbers 139311, 08BR001591/DF and 08BR002483/DF from the Brazilian Ministry of Environment.

\section{References}

Adams J, Rothman ED, Kerr WE, Paulino ZL (1977) Estimation of the number of sex alleles and queen matings from diploid male frequencies in a population of Apis mellifera. Genetics 86: 583-596

Aidar DS, Kerr WE (2001) Número de alelos XO em uma população de Melipona quadrifasciata anthidioides Lepeletier (Hymenoptera, Apidae, Meliponinae). Rev Bras Zool 18:1237-1244

Alves DA, Imperatriz-Fonseca VL, Francoy TM et al (2009) The queen is dead-long live the workers: intraspecific parasitism by workers in the stingless bee Melipona scutellaris. Mol Ecol 18:4102-4111

Alves RMO, Carvalho CAL, Souza BA, Santos WS (in press) Areas of natural occurrence of Melipona scutellaris Latreille, 1811 (Hymenoptera: Apidae) in the State of Bahia, Brazil. An Acad Bras Cienc

Biesmeijer JC, Roberts SPM, Reemer M et al (2006) Parallel declines in pollinators and insect-pollinated plants in Britain and the Netherlands. Science 313:351-354

Brown JC, Albrecht C (2001) The effect of tropical deforestation on stingless bees of the genus Melipona (Insecta: Hymenoptera: Apidae: Meliponini) in central Rondonia, Brazil. J Biogeogr 28:623-634

Camargo CA (1979) Sex determination in bees. XI Production of diploid males and sex determination in Melipona quadrifasciata. J Apic Res 18:77-84

Camargo JMF, Pedro SRM (2007) Meliponini Lepeletier, 1836. In: Moure JS, Urban D, Melo GAR (eds) Catalogue of Bees (Hymenoptera, Apoidea) in the Neotropical Region. Sociedade Brasileira de Entomologia, Curitiba, pp 272-578

Carvalho GA (2001) The number of sex alleles (CSD) in a bee population and its practical importance (Hymenoptera: Apidae). J Hymenopt Res 10:10-15

Carvalho-Zilse GA, Kerr WE (2004) Natural substitutions of queens and flight distance of males in tiúba (Melipona compressipes fasciculata Smith, 1854) and uruçu (Melipona scutellaris Latreille, 1811) (Apidae, Meliponini). Acta Amazonica 34:649-652

Carvalho-Zilse GA, Costa-Pinto MFF, Nunes-Silva CG, Kerr WE (2009) Does beekeeping reduce genetic variability in Melipona scutellaris (Apidae, Meliponini)? Genet Mol Res 8:758-765

Castro MS (2002) Bee fauna of some tropical and exotic fruits: potencial pollinators and their conservation. In: Kevan P, Imperatriz-Fonseca VL (eds) Pollinating bees-the conservation link between agriculture and nature. Ministry of Environment, Brasília, pp 275-288

Chapman RE, Bourke AFG (2001) The influence of sociality on the conservation biology of social insects. Ecol Lett 4:650-662

Cook J, Crozier RH (1995) Sex determination and population biology in the Hymenoptera. Trends Ecol Evol 10:281-286

Cornuet JM (1980) Rapid estimation of the number of sex alleles in panmictic honeybee populations. J Apic Res 19:3-5
Cortopassi-Laurino M, Imperatriz-Fonseca VL, Roubik DW et al (2006) Global meliponiculture: challenges and opportunities. Apidologie 37:275-292

Costanza R, d' Arge R, de Groot R et al (1997) The value of the world's ecosystem services and natural capital. Nature 387:253-260

Crozier RH (1976) Counter-intuitive property of effective population size. Nature 262:384

De la Rúa P, Jaffé R, Dall'Olio R et al (2009) Biodiversity, conservation and current threats to European honeybees. Apidologie 40:263-284

Efron B, Tibshirani R (1986) Bootstrap methods for standard errors, confidence intervals, and other measures of statistical accuracy. Statistical Science 1:54-77

Efron B, Tibshirani R (1993) An introduction to the bootstrap. Chapman\& Hall/CRC, Florida

Efron B, Tibshirani RJ (1998) An Introduction to Bootstrap. Chapman \& Hall, London

Estoup A, Solignac M, Cornuet JM (1994) Precise assessment of the number of patrilines and of genetic relatedness in honey bee colonies. Proc R Soc Lond B 258:1-7

Estoup A, Garnery L, Solignac M, Cornuet JM (1995) Microsatellite variation in honey bee (Apis mellifera L.) populations: hierarchical genetic structure and test of the infinite allele and stepwise mutation models. Genetics 140:679-695

Goulson D, Lye GC, Darvill B (2008) Decline and Conservation of Bumble Bees. Annu Rev Entomol 53:191

Green CL, Oldroyd BP (2002) Queen mating frequency and maternity of males in the stingless bee Trigona carbonaria Smith. Insectes Soc 49:196

Hasselmann M, Gempe T, Schiott M et al (2008) Evidence for the evolutionary nascence of a novel sex determination pathway in honeybees. Nature 454:519-522

Heard TA (1999) The role of stingless bees in crop pollination. Annu Rev Entomol 44:183-206

Heimpel GE, de Boer JG (2008) Sex determination in the Hymenoptera. Annu Rev Entomol 53:209-230

Kearns CA, Inouye DW, Waser NM (1998) Endangered mutualisms: The conservation of plant-pollinator interactions. Annu Rev Ecol Syst 29:83-112

Kerr WE (1986) Mutation in bees 3. Application in bee populations of a mutation rate of $\mu=1.6 \times 10^{-6}$. Brazil J Genet 9:1-10

Kerr WE (1987) Sex determination in bees XXI. Number of xo-heteroalleles in a natural population of Melipona compressipes fasciculata Apidae. Insect Soc 34:274-279

Kerr WE, Vencovsky R (1982) Bee breeding. 1. Effect of the number of colonies. Brazil J Genet 5:279-285

Kimura M, Crow J (1964) The number of alleles that can be maintained in a finite population. Genetics 49:725

Laidlaw HH, Gomes FP, Kerr WE (1956) Estimation of the number of lethal alleles in a panmictic population of Apis mellifera $\mathrm{L}$. Genetics 41:179-188

Michener CD (1974) The social behavior of the bees. Harvard University Press, Massachusetts

Nogueira-Neto P (2002) Inbreeding and building up small populations of stingless bees (Hymenoptera, Apidae). Rev Bras Zool 19: $1181-1214$

Owen RE, Owen ARG (1989) Effective population size in social Hymenoptera with worker-produced males. Heredity 63:59-65

Packer L, Owen R (2001) Population genetic aspects of pollinator decline. Conserv Ecol 5:4

Page RE, Marks RW (1982) The population genetics of sex determination in honey bees-Random mating in closed populations. Heredity 48:263-270

Paxton RJ, Weissschuh N, Quezada-Euán JJG (1999) Characterization of dinucleotide microsatellite loci for stingless bees. Mol Ecol 8:690-692 
Paxton RJ, Bego LR, Shah MM, Mateus S (2003) Low mating frequency of queens in the stingless bee Scaptotrigona postica and worker maternity of males. Behav Ecol Sociobiol 53: 174-181

Peters JM, Queller DC, Imperatriz-Fonseca VL, Strassmann JE (1998) Microsatellite loci for stingless bees. Mol Ecol 7:784-787

Peters JM, Queller DC, Imperatriz-Fonseca VL et al (1999) Mate number, kin selection and social conflicts in stingless bees and honeybees. Proceedings of the Royal Society B: Biological Sciences 266:379

Ross KG, Fletcher DJC (1986) Diploid male production-a significant colony mortality factor in the fire ant Solenopsis invicta (Hymenoptera: Formicidae). Behav Ecol Sociobiol 19:283-291

Schmid-Hempel P, Schmid-Hempel R, Brunner PC et al (2007) Invasion success of the bumblebee, Bombus terrestris, despite a drastic genetic bottleneck. Heredity 99:414-422

Slaa EJ, Sanchez Chaves LA, Malagodi-Braga KS, Hofstede FE (2006) Stingless bees in applied pollination: practice and perspectives. Apidologie 37:293-315

Tóth E, Strassmann JE, Nogueira-Neto P et al (2002) Male production in stingless bees: variable outcomes of queen-worker conflict. Mol Ecol 11:2661-2667

Tóth E, Queller DC, Dollin A, Strassmann JE (2004) Conflict over male parentage in stingless bees. Insectes Soc 51:1-11
Visscher PK (1989) A quantitative study of worker reproduction in honey bee colonies. Behav Ecol Sociobiol 25:247-254

Wenseleers T, Alves DA, Francoy TM et al (2011) Intraspecific colony take-over by unrelated queens in a highly eusocial bee. Biol Lett. doi:10.1098/rsbl.2010.0819

Whiting PW (1943) Multiple alleles complementary sex determination of Habrobracon. Genetics 28:365-382

Woyke J (1963) What happens to diploid drone larvae in a honeybee colony. J Apic Res 2:73-75

Yokoyama S, Nei M (1979) Population dynamics of sex-determining alleles in honey bees and self-incompatibility alleles in plants. Genetics 91:609-626

Zayed A (2009) Bee genetics and conservation. Apidologie 40: 237-262

Zayed A, Packer L (2005) Complementary sex determination substantially increases extinction proneness of haplodiploid populations. Proc Natl Acad Sci USA 102:10742

Zayed A, Roubik D, Packer L (2004) Use of diploid male frequency data as an indicator of pollinator decline. Proc R Soc Lond B 271:S9-S12

Zayed A, Constantin SA, Packer L (2007) Successful biological invasion despite a severe genetic load. PLoS ONE 2:e868 